\title{
Correction to: Cellular Trafficking of Amyloid Precursor Protein in Amyloidogenesis Physiological and Pathological Significance
}

\author{
Noralyn Basco Mañucat-Tan ${ }^{1} \cdot$ Khalil Saadipour $^{2} \cdot$ Yan-Jiang Wang ${ }^{3} \cdot$ Larisa Bobrovskaya $^{1} \cdot$ Xin-Fu Zhou $^{1}$
}

Published online: 14 June 2018

(C) Springer Science+Business Media, LLC, part of Springer Nature 2018

\section{Correction to: Mol Neurobiol}

https://doi.org/10.1007/s12035-018-1106-9

The original version of this article unfortunately contained mistake. The old version of Fig. 3 was published.

The correct Fig. 3 is hereby given below.

The online version of the original article can be found at https://doi.org/ 10.1007/s12035-018-1106-9

Noralyn Basco Mañucat-Tan

noralyn.manucat@gmail.com

$\triangle$ Xin-Fu Zhou

Xin-Fu.Zhou@unisa.edu.au

1 School of Pharmacy and Medical Sciences, Sansom Institute for Health Research, University of South Australia, Adelaide, South Australia 5000, Australia

2 Departments of Cell Biology, Physiology and Neuroscience, and Psychiatry, Skirball Institute of Biomolecular Medicine, New York University Langone School of Medicine, New York, NY, USA

3 Department of Neurology and Center for Clinical Neuroscience, Daping Hospital, Third Military Medical University,

Chongqing 400042, China 


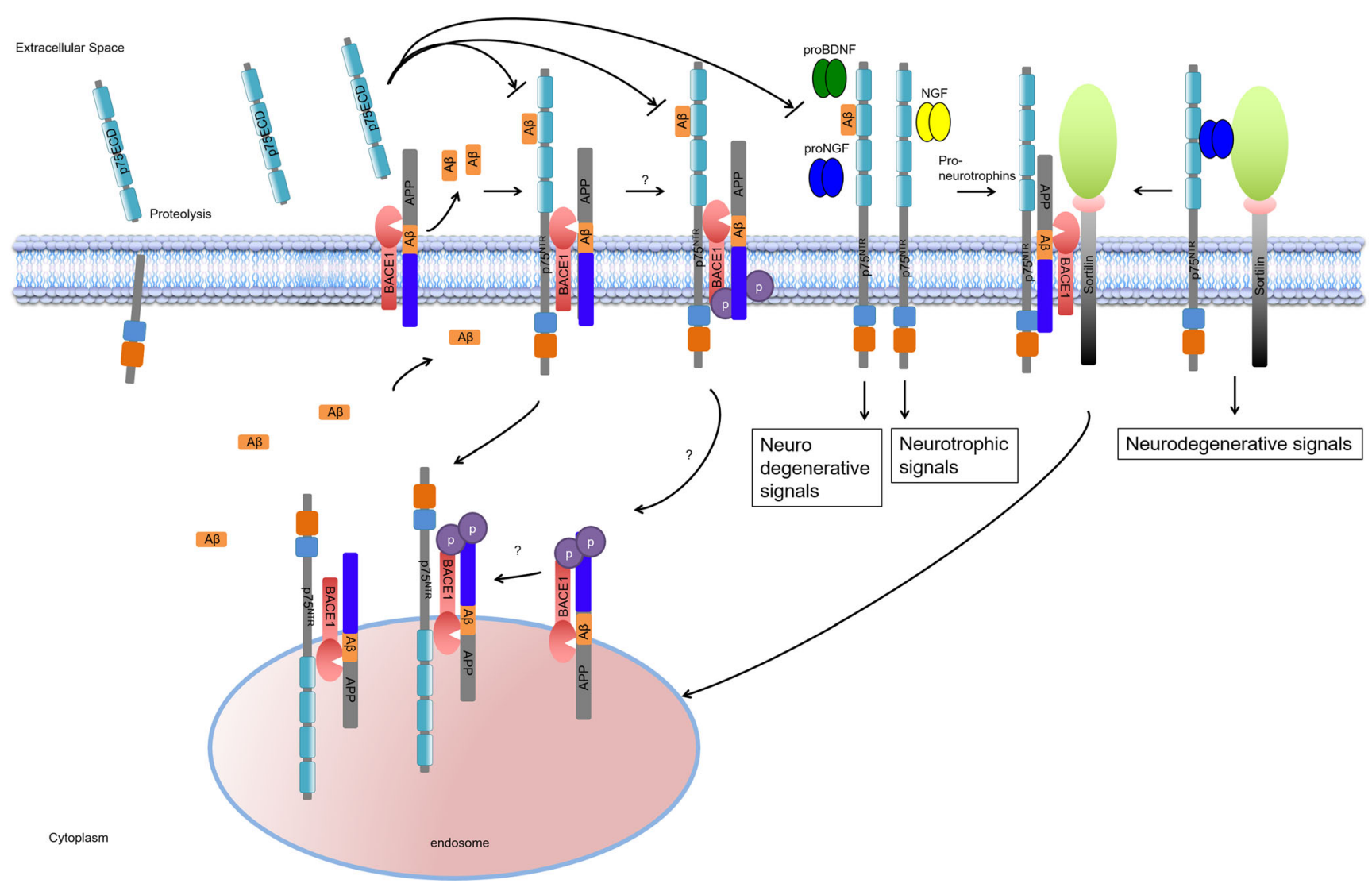

